\title{
Message Discrimination on the Basis of Gender for BeautyProducts' TV Commercials
}

\author{
Saima Zareen1 ,DrArshad Ali 2 Asma Rana3 \\ ${ }^{1,2,3}$ Department of Communication Studies and Media Center, University of Gujrat,, Pakistan
}

\begin{abstract}
This study aims to determine the message discrimination on gender on the basis of beauty product's $T V$ commercials. To achieve the objectives of the study target population was selected from the University of Gujrat with the sample size of 120 in which 75 were males and 75 were females. This study revealed resulthat both males and females have high exposure towards TV and both are influenced by the TV commercials of beauty products.
\end{abstract}

\section{Introduction}

Television is an audio-visual communication medium. It has broad reach and stronger influence upon people and culture. It is most acceptable that each households watch Television and it has become a most effective medium to reach large number of audience. It's very hard to imagine a word without TV. It is the most significant medium of providing information, education and entertainment. Advancement in technology and increase in competition among viewers are making television more efficient. "The transmission of dynamic or sometimes static images, generally with accompanying sound, via electric or electromagnetic signals "(Online Dictionary.com, 2012).

The audio visual character of Television makes it a magic medium which allows us to watch the world and this quality makes television images more memorable. Television has powerful visual nature which this powerful visual nature helps television to create vivid impressions in our minds which in turn leads to emotional involvement which makes television more memorable. (TV as a mass medium).It has ability to reach a massive audience at any given time for the purpose of entertainment, news, political statement or (mainly) advertising.

Television has vast potential as an audio visual communicator. The impacts of TV are very important because it has ability to communicate with large number of audience by combining emotions, words, color and personality etc. Television advertisement play a vital role to introduce the product for people and then make them familiarize with the product and also realistic to purchase it. Therefore, advertisement have become a great deal of attention in last 10 to 15 years (Pandey, 2007) ${ }^{1}$.

The best mean of communicating information through television is advertising. It's the effective mean of introducing product and their services that how it can improve the life style which in turn persuade the customer to purchase the product. Television commercials, TV ad provides significant revenue to television networks. Television commercials have a great influence upon viewing public that no political campaign will be successful without television advertising.

\section{Advertisement}

Advertising is the best means to promote goods or services to the public. The basic aim of advertiser is to increase sales of these goods or services by drowning people's attention to them and showing them in a favorable light (Petley, 2003). Advertising can also be defined as a paid for mass media communication and a means of managing and controlling to consume market at least cost (Bierley, 1995).

Advertising hanged the world today as we see advertising industry has grown tremendously over these years. If we look around we will come to know that we are surrounded by advertisements and put a great impact these kinds of brands and items we use. Today Advertisements have potential to make or break any brands and therefore they are one of the important elements of our social life (Worldoffemales, 2012).

It intended to persuade the consumer to purchase particular brand. An advertisement includes some of the product, services and its significance. Different types of media can be used to deliver messages for large and diverse audience. A successful advertisement always can attract the attention of customer including jingles, $\operatorname{logo}$, and slogan in it. It also enhances the memory ability of advertisement.

An advertisement or commercial should always have appeal and should always be relevant to the lives of target audience. It must have ability to stimulate the public's desire and persuade them to take some action.In the contemporary world, the universal presence of advertising is increasingly influencing people's daily life; it affects their world views, knowledge, motivations, experience, expectations and sense of identity (Chafai, 2008). Advertising is the foundation and economic lifeblood of the mass media.The primary purpose of mass 
media is to deliver an audience to advertiser, just as the primary purpose of Television program is to deliver an audience for commercials (Kilbourn, 1990)a.

\section{Television commercials:}

Television commercial is usually a short clip of video, describes the qualities of product that is being sell. It's usually targeted to a certain groups of people convinced to buy the product. It is short phrase and appeal that is memorable and a symbol or logo that represents a product or company. The main purpose of commercial is to reach the target audience and to convince the purchase that particular product.

Ruseel\&Lsane (1999) stated that commercials are considered a part of communication strategies for marketing that are used for the purpose of drowning people's attention towards commercials and influence them to purchase advertised goods and services but according to Thanatporn (2011) commercial is used in trade and culture as a marketing tool and not only reflects but also influences the people's lifestyle, choices and social trends.

Arens et al. (2008) in 2006 proposed that adult viewers rated TV commercials as the most authoritative, influential and persuasive advertising medium as compared with other media such as radio, newspaper, magazine and the Internet. The research showed that over half of the viewers believe that TV is the most authoritative commercial source as compared with newspaper (23\%), magazine $(11.4 \%)$, radio $(9.6 \%)$ and the Internet (4.5\%) (Khattiyanon, 2011). Ehow contributor (2012) stated that television commercials have become a phenomenon that can set the norms and change the lifestyle of people. More consumers who have continuous exposure to television convinced that certain purchases and products make them more socially acceptable.

\section{Message Discrimination:}

The concept of message discrimination was originally developed as a mean of determining actual units of content that individuals extract from encounters with mass media.

Messages can be discriminated on the basis of demographic factors (gender, race, education, ethnicity, age etc.)These demographic factors are very important for television advertisers. Demographics tells about potential advertisers exactly who watches certain shows. For example, $75 \%$ of people who watch Judge Judy are female. Therefore, advertisers who are trying to sell products to women are more likely to buy advertising slots during the show.Sports are primarily watched by men, so products targeted to men are advertised during sports programs (Wanttoknowit, 2012).

As this research study is related to the Message discrimination on the basis of gender for beauty product TV commercials. So, this study is concerned with Television commercials of beauty products. How these commercials are discriminated with male and female?

\section{Rationale of study:}

This is a normal fact that beauty matters for everyone. People use different means to look beautiful and commercials have played a greater role in this way. Commercials on television persuade the audience to purchase the beauty products because it's make help to enhance their appearance and to look beautiful.According to Aurdeyet.al, (2007)

"Everyone has desire to look beautiful. We are living in global world that sets stereotypes that becomes models now. These stereotypes or models are overrepresented all around us in magazines, fashion shows, commercials that or even at work or at school. So, it has become a fact that everybody wants a perfect skin and body like that models for a perfect life."

In the 21st century,advancement and development in Science technology provides a lot of gifts and one of them is mass media for people. Mass media makes people very conscious about their appearance. Now every body has desire to look good than its original self. In the U.S Food And Drug administration (FDA,2012) which regulates cosmetics, defines cosmetics as, "intended to be applied to the human body for cleansing, beautifying, promoting attractiveness or altering the appearance without affecting the body's structure of function".

Olzyk\&Twardowska (2000) stated that everybody has desire to look good but the term of beauty is usually related to female and women are considered the main target audience for manufacture and commercials are designed to sell the products particularly to women. But men are also becoming conscious about their look .A new study by Daily Mail (2012), revealed that well groomed men are now turning to female beauty products in order to maintain their appearance.

\section{Significance of Study:}

This study is conducted to find the impact of beauty product's in TV commercials on the basis of message discrimination both male and female. As it is the common perception that women are more concerned about their beauty and appearance than men so it will help us to know whether it is true or not and how much male and female are influenced by television commercials of beauty products. Advertisers and marketers are 
more concerned to know about the people's motives about advertisement through which advertisers can adopt different strategies to influence the audience. This will help them to identify their target audience and used the factors that influence them effectively in any advertisement so those can be worked on.

\section{Statement of problem:}

Men and women have different tendencies are being affected by advertisements. Why companies do not know exactly that which customer group, men or women are easier to influence by marketing campaigns. Therefore, the advertising budget is not spent accordingly to come up with a precise promotional campaign needed. If targeting men is easier, then the marketing should be done accordingly and if affecting women is easier, then the marketing campaign should be tailor made in order to reach that customer segment in a more effective manner (Haque, 2012).It is a normal fact that male and female have tendencies to perceive TV commercials differently so this study is conducted to describe the message discrimination of gender on the basis of commercials beauty products.

\section{Theoretical Framework: \\ Social learning theory:}

Social learning theory is derived from Albert Bandhura (1977). It is the most famous theory emphasize on the importance of learning from environment through observation. As this study is related to perception of viewers through TV commercials and observation of behavior on TV commercials may have effect on viewer's own behavior in their life.

\section{Cultural feminism:}

Cultural feminism is a theory emphasizes and praises the positive aspects of women. Sociology encyclopedia (2012) stated that Cultural feminism seeks to understand women's social locations in society by concentrating on gender differences between women and men.

\section{Gender schema theory:}

The distinction between males and females serve as basic organizing principle for every human culture. A schema is a cognitive structure, a -network of associations that organizes and guides an individual perception. Bem has proposed an explanation of how one's gender (masculine or feminine) affects the individual's cognitive structure (a network of associations that organizes and guides the individual's perception).

This study also emphasize on the effects of TV commercials on gender. As society decides the role of gender so they perceive according to the characteristics that decided by society. So, males and females perceive things differently.

\section{Literature review}

Literature review is actually consisting of materials related to present study.According to Bumrungkitjareon\&Tanasansopin (2011) "A literature review is used to explain the reader the range of definitions and concepts that are available within relevant literature and then choose one that seems to you the best suited for your research project". A literature review is an account of what has been published on a topic by accredited scholars and researchers (writing).Many of the researches have been conducted on effects of television commercials before this. A television commercial is used to spark interest in a product or services; without this influential and dominant form of advertisements, the majority of the companies and their respective products and services would not maximize their ability to reach various consumer bases (commercial. laws).

\section{Effects of TV commercials on consumer:}

Many of the researches have been conducted to see the influence of advertisement or TV commercials on consumer.The findings of these study support the current study that consumers are very much affected through TV advertisement.TV commercials have great ability to create a desire in Audience and persuade them to buy advertised products.

Bashir (2009) conducted a research to find out the effects of advertisements on consumer behavior. The study find out that advertisement is reliable source of knowledge for consumer in everywhere. Advertisement mostly effect income group and repetition of message cannot effect the consumer attitude .Results revealed that advertisement once in a life time can persuade the consumer to buy a product. Another study by (Anna j., 2008) supported that female are more influenced by media images such as television commercials than males. Results of this study indicated statistical significant with more females $93(46 \%)$ than males $28(25 \%)$ indicating yes media influenced the way they responded. The result of this study supported that males and females are college students are influenced by the media images of the ideal males and females being portrayed by the media. Therefore, they prefer to buy products advertised in television. But Kotwal, Gupta \&Devi, 2008 find out in their 
research that adolescents. Result of this study also revealed that female are more influenced by media images but in different ways influence on advertisement have powerful behavior of adolescent girls towards television advertisement.

\section{Effects of TV advertisement on women:}

During studying the literature many of the studies found who were mostly conducted on effects of advertisement on females. Television advertisements put more impact on viewers than others. Television advertisement can have a powerful influence on adolescents, food preferences, consumption and behavior. This study believes that one impact is equivalent to one member of the target audience viewing one commercial spot. The result of this study revealed that the girls viewed TV advertisements with interest and found them entertaining and informative (kotwal, Gupta, Devi, 2008) ${ }^{2}$

Ashudazzaman\&Rahman(2011) conducted a research on television advertisement on the buying pattern of women. Television advertisement has a powerful influence on purchasing behavior of female consumer and it is the most convenient way to reach female consumer because television is most recreation source for women. Television advertisement is the most powerful among other advertising media.

Mahajan (1997) studied the impact of media on lifestyle of adolescents and found that media especially television and satellite channels certainly affects the lifestyle of individuals. They tend to buy the product advertised through the media, irrespective of its cost. The way of presentation matters in the case of food items whereas in case of clothing, designer label mattered.

Khattak\& Khan (2009) also conducted a research to examine general attitude of college students towards consequences and impacts of television advertising in Pakistan. This study showed that marketers and businessman use advertising techniques to persuade the potential customer to purchase products. Advertisers are also devising the ways to make advertisement more effective. The results of this research revealed that there is significant attitude of student towards television advertising but some of them also argued that television advertising promotes materialism.

\section{Beauty products influence on females:}

Previous research studies conducted to see the influence of beauty product's on females selected as target audience.

A research on topic Attraction of students toward beauty products conducted by Raza\& Ali in 2011.The purpose of this study to measure the attraction of university students towards beauty products.

Deceptive analysis, Pearson's correlation technique and models of linear regression was used. Out of 142 respondents 47 were male respondents, which were $33.1 \%$ and female respondents were $66.9 \%$ of total respondents. After the analysis and results study concluded that a positive and significant relationship exists between beauty advertising and buying behavior of students.

Oakley (2009) conducted a research on An Evaluation of current techniques in cosmetic advertising and an assessment of their effectiveness on the contemporary consumers. The focused in his dissertation on evaluation of current techniques in cosmetic advertising to access their advertising on consumers. Both qualitative and quantitative techniques were used. A self completion questionnaire and Semi-structured interviews were also carried out together information from target audience. A pilot questionnaire was carried out on three males and three females.68.3\% of respondents disapproved lash inserts that consumers needs aspiration advertising. $88 \%$ claimed not to be influenced by celebrity endorsement. $48 \%$ of the women reported the reason to wore cosmetics because it feels them more confident and $1.1 \%$ females surveyed actually bought the brand. This study recommended that consumers should be educated and more sophisticated methods of advertising should be used to persuade the consumer. Not only advertising industry needs to change but consumer should also take responsibility to for their own actions. Most of the researches have conducted on female's behavior towards beauty products but few of the researches have also done on male's behavior towards male's purchasing behavior towards cosmetics.

\section{Effects of TV beauty products on males:}

Bumrungkitjareon\&Tanasansopin (2011) conducted a study on male's intentions towards cosmetic,to see now male more concerned about their image than before. Male's cosmetic industry is one of the fastest growing particularly in skin care products and this behavior has become a new trend now a days. Business of men's cosmetic has becoming boom due to the increasing demands of men's cosmetics.

A research study was conducted by haque (2012), to see the effects of advertisement on the buying behavior of male and female it was an exploratory study conducted through quantitative analysis .this study explored that male and female both influenced by advertisement and it strongly influence their buying behavior but females are more influenced through celebrity endorsed and emotional themes but male were not influence and don't believe on TV commercials. 
This study found at the time of purchasing people prefer to brand recall as compared to TV commercials products and females have better brand recall as compared to male. Moungkhem\&surakiatpinyo (2010) founded that the number of men who use skin care products and who don't are not much in difference. The study was conducted to find out the reasonable impact of perception on the relationship between variables and consumer behavior. Results of this study revealed that men use skin care products to better their skin while men mostly do not use this product because they think beauty products are no necessary, very lavish and expensive also.

The objectives of this thesis are:

\section{Objectives of study}

1. To explore the exposure of students at University of Gujrat towards the commercials of beauty products.

2. To find out the influence of beauty product commercials on the behavior of UOG students.

3. To examine the perception difference on the basis of gender about the beauty product commercials

\section{Hypothesis:} between Gujrat university students.

Following study has been hypnotized as

$\mathrm{H}: 1$ Females are more influenced by commercials of beauty products as compared to male.

$\mathrm{H}$ : 2 Male are more influenced by commercial of beauty product as compared to female.

Research question

Q: 1 How beauty commercial products affect student (Gujrat University) mind to buy product?

Q: 2 what is difference perception of beauty product commercials on the basis of gender?

\section{Methodology}

Survey research method was adopted in this research.

Population

Population in this study is University of Gujrat and its surroundings. Sample

In the study universe is students, University of Gujrat.

\section{Sampling Method:}

In this study probability sampling is used. For data collection samples are stratified according to the gender both male and female who watch television commercials. On the other hand, convenience sampling is also used, that is based on non-probability sampling.

\section{Sample size:}

Convenience methods were used for collection of data from the target population to meet the requirements of study.

Data Presentation:

Data is presented in Univariate frequency in shape of graphics and tables along with interpretation to make it clear and understandable. Collected data was entered and interpreted by SPSS. The tables below show frequency and percentage of response cat

How often do you watch television * Gender Cross tabulation

\begin{tabular}{|l|r|r|r|}
\hline & Gender & & \multicolumn{1}{|c|}{ Total } \\
\hline & male & female & \\
\hline Frequently & 35 & 36 & 71 \\
\hline Sometimes & 20 & 15 & 35 \\
\hline Rarely & 3 & 9 & 12 \\
\hline Never & 2 & 0 & 2 \\
\hline & 60 & 60 & 120 \\
\hline
\end{tabular}




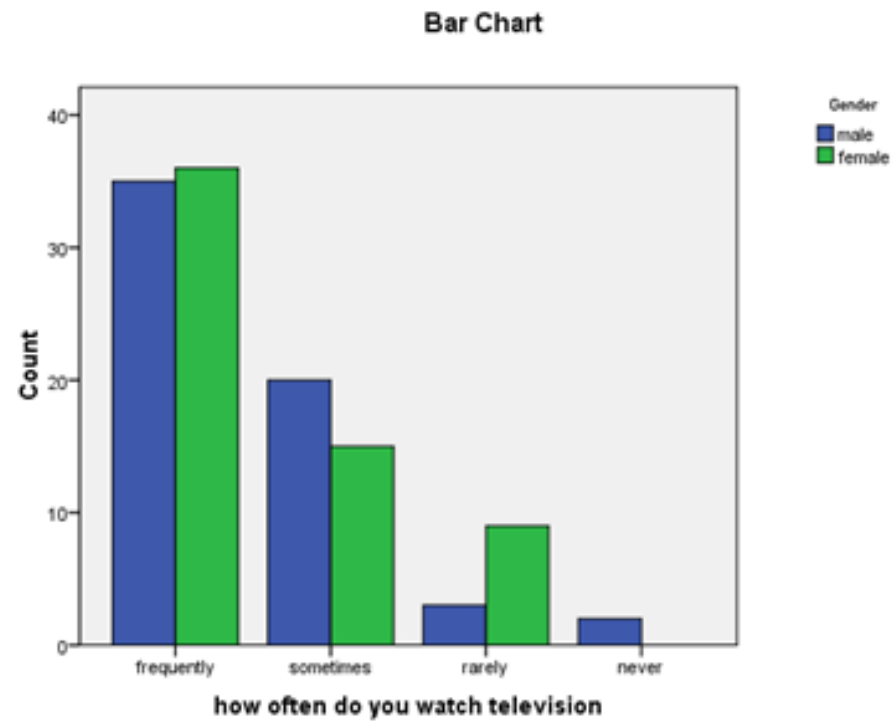

Table 1 was designed to find out the exposure of audience towards TV. Results shows that $71 \%$ of the total respondents had exposure towards TV in which $36 \%$ of are female and $35 \%$ are male frequently watch TV.9\% females and 3\% males rarely watched TV. While $15 \%$ females and $20 \%$ male watched TV sometime and only $25 \%$ of males had never watched TV ever. It shows that majority of the audience have exposure of TV.

\section{How often do you watch television commercials of beauty products * Gender Cross tabulation}

\begin{tabular}{|l|r|r|r|}
\hline & Gender & & \multicolumn{1}{|c|}{ Total } \\
\hline & male & female & \\
\hline Frequently & 15 & 29 & 44 \\
\hline Sometimes & 14 & 16 & 30 \\
\hline Rarely & 25 & 13 & 38 \\
\hline Never & 6 & 2 & 8 \\
\hline & 60 & 60 & 120 \\
\hline
\end{tabular}

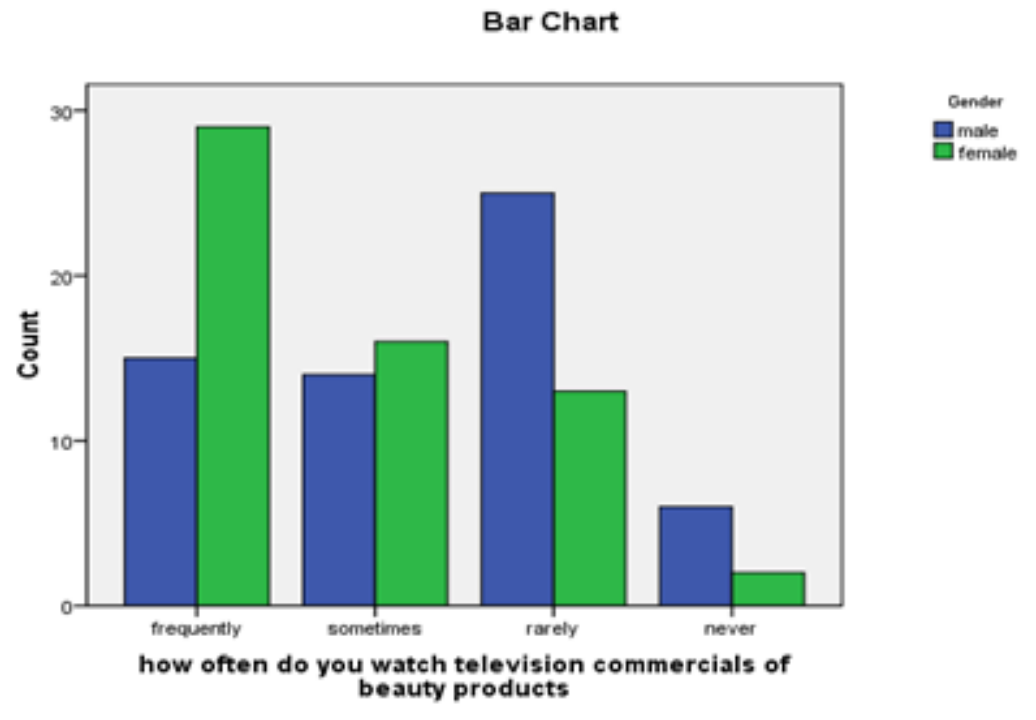

Question no.2 was designed to identify that to what extent audiences watch TV commercials of beauty products. And Table 2.shows that $44 \%$ of respondent's had exposure towards beauty product's TV commercials. In which $29 \%$ are females who frequently watched it as compared to $15 \%$ males. While $16 \%$ males and $14 \%$ females watched it sometimes and only $2 \%$ females and $6 \%$ males had never watched beauty product's TV commercials. It means that females are more likely to watch TV commercials of beauty products. 
I am interested in TV commercials * Gender Cross tabulation

\begin{tabular}{|l|r|r|r|}
\hline & \multicolumn{1}{|c|}{ Gender } & & \multicolumn{1}{|c|}{ Total } \\
\hline & \multicolumn{1}{|c|}{ male } & female & \\
\hline Agree & 25 & 27 & 52 \\
\hline strongly agree & 0 & 21 & 21 \\
\hline Neutral & 24 & 9 & 33 \\
\hline Disagree & 11 & 3 & 14 \\
\hline & 60 & 60 & 120 \\
\hline
\end{tabular}

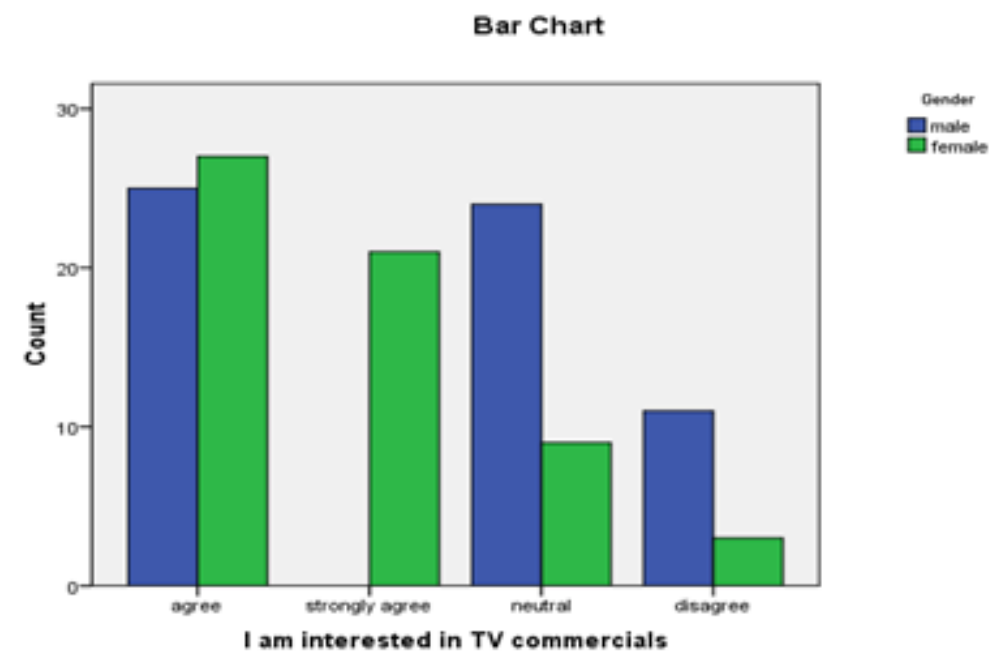

According to the table 3.majority of the respondents were interested in TV commercials in which $27 \%$ were females and $25 \%$ males. While only $9 \%$ of the males and $24 \%$ of the females had neutrally responded on this question. Out of $21 \%$ of respondents who had chosen strongly agreed response, $21 \%$ were females only males were $0 \%$.and respondents who disagreed were $3 \%$ males and $11 \%$ females.

\section{I attach great importance to beauty products * Gender Cross tabulation}

\begin{tabular}{|l|r|r|r|}
\hline & \multicolumn{1}{|c|}{ Gender } & & \multicolumn{1}{c|}{ Total } \\
\hline & male & female & \\
\hline Agree & 17 & 20 & 37 \\
\hline strongly agree & 5 & 20 & 25 \\
\hline Neutral & 22 & 13 & 35 \\
\hline Disagree & 13 & 6 & 19 \\
\hline strongly disagree & 3 & 1 & 4 \\
\hline & 60 & 60 & 120 \\
\hline
\end{tabular}

Bar Chart

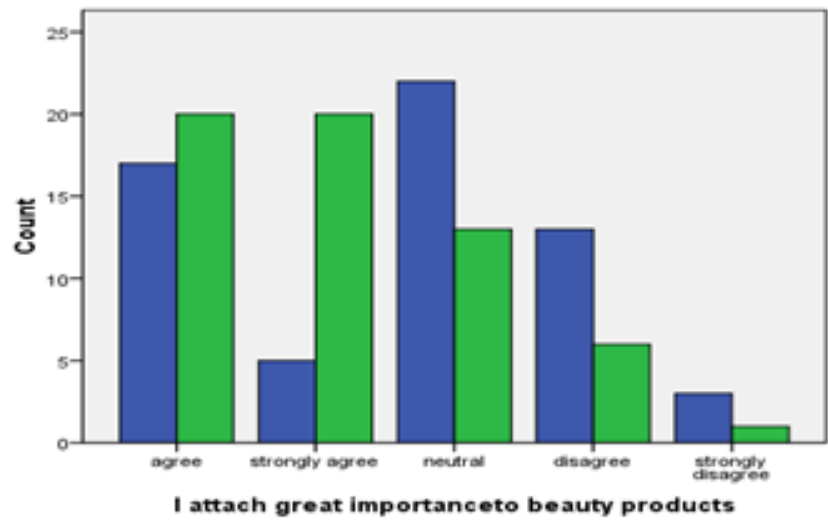


This table.4 was designed to know the importance of beauty products. Respondents who had chosen agreed response were $20 \%$ female and $17 \%$ male. Females were $20 \%$ and males were $5 \%$ who strongly agreed. And $13 \%$ females and $22 \%$ males gave neutral importance.6\% female and $13 \%$ female were disagreed.1\% females and $3 \%$ strongly disagreed on this. It means female attach more importance to beauty products as compared to females.

I am influenced by the TV commercials of beauty products * Gender Cross tabulation
\begin{tabular}{|l|r|r|r|}
\hline & Gender & & \multicolumn{1}{|c|}{ Total } \\
\hline & male & female & \\
\hline Agree & 12 & 31 & 43 \\
\hline strongly agree & 2 & 6 & 8 \\
\hline Neutral & 25 & 11 & 36 \\
\hline Disagree & 21 & 8 & 29 \\
\hline strongly disagree & 0 & 4 & 4 \\
\hline & 60 & 60 & 120 \\
\hline
\end{tabular}

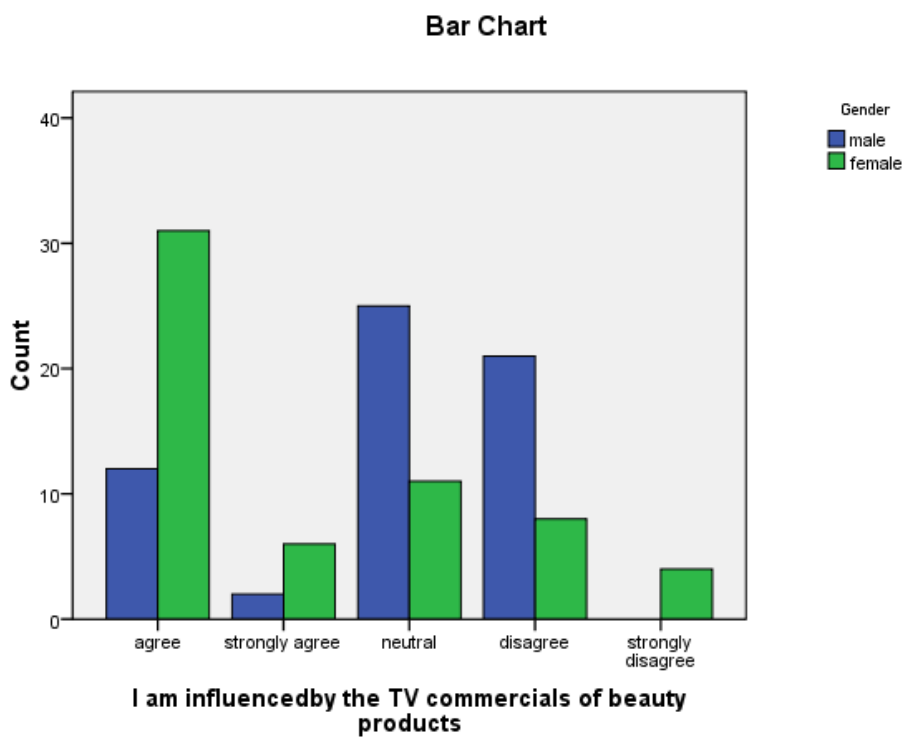

This above tablewas set to know that to what extent male and female influenced by beauty products .majority of the female $31 \%$ agreed that they are influenced by TV commercials of beauty products. while only $12 \%$ males agreed on this question and $6 \%$ female and $2 \%$ males were strongly agreed $.11 \%$ males and $25 \%$ females gave neutral response and $8 \%$ females and $21 \%$ males disagreed on any kind of influence by beauty products. $4 \%$ female strongly disagreed and while not any one males give strongly disagreed response. It means that females have more influence through beauty products.

I use beauty products to enhance my appearance * Gender Cross tabulation

\begin{tabular}{|l|r|r|r|}
\hline & Gender & & \multicolumn{1}{|c|}{ Total } \\
\hline & male & female & \\
\hline Agree & 20 & 23 & 43 \\
\hline strongly agree & 9 & 13 & 22 \\
\hline Neutral & 17 & 15 & 32 \\
\hline Disagree & 13 & 7 & 20 \\
\hline strongly disagree & 1 & 2 & 3 \\
\hline & 60 & 60 & 120 \\
\hline
\end{tabular}




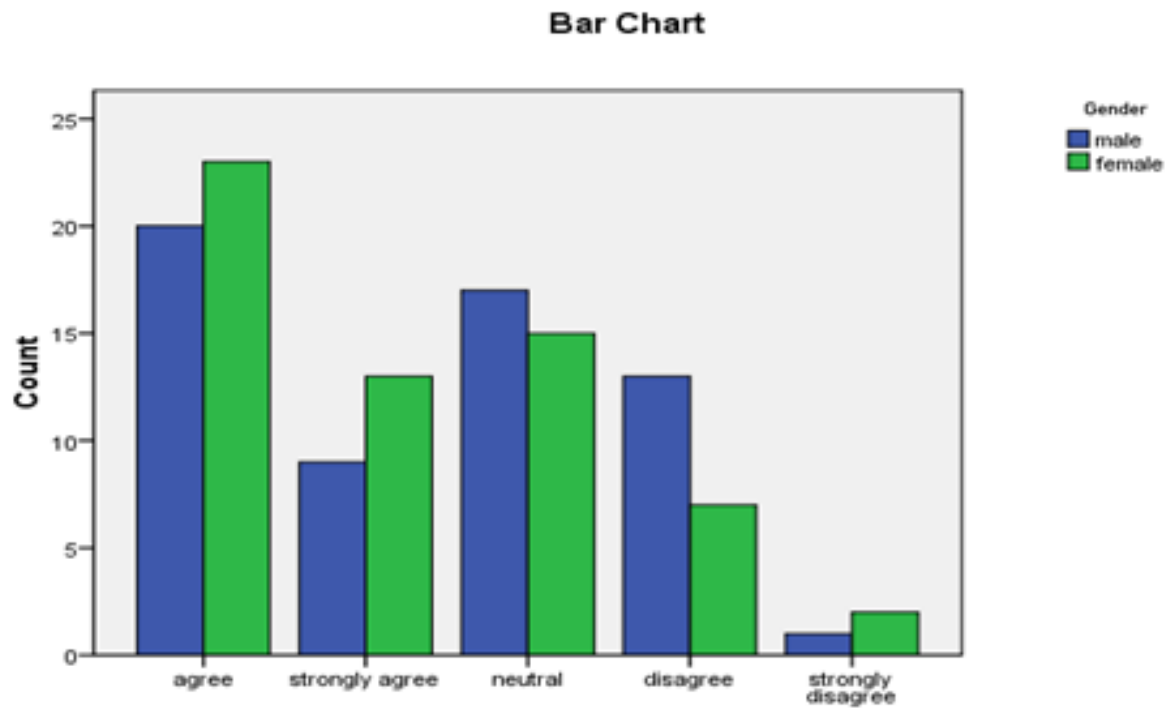

I use beauty productsto enhance my appearance

This table depicts that how much respondents use beauty products to enhance their appearance. $23 \%$ females and $20 \%$ gave agreed response. $22 \%$ respondents were strongly disagreed on this in which $13 \%$ were females and $9 \%$ were males. $15 \%$ females and $17 \%$ males neutrally responded on this. While only $2 \%$ females and $1 \%$ males strongly disagreed on this.

\section{Beauty of the model influences my buying behavior to purchase beauty products * Gender Cross} tabulation

\begin{tabular}{|l|r|r|r|}
\hline & Gender & & \multicolumn{1}{|c|}{ Total } \\
\hline & male & female & \\
\hline Agree & 12 & 22 & 34 \\
\hline strongly agree & 5 & 7 & 12 \\
\hline Neutral & 30 & 13 & 43 \\
\hline Disagree & 12 & 16 & 28 \\
\hline strongly disagree & 1 & 2 & 3 \\
\hline & 60 & 60 & 120 \\
\hline
\end{tabular}

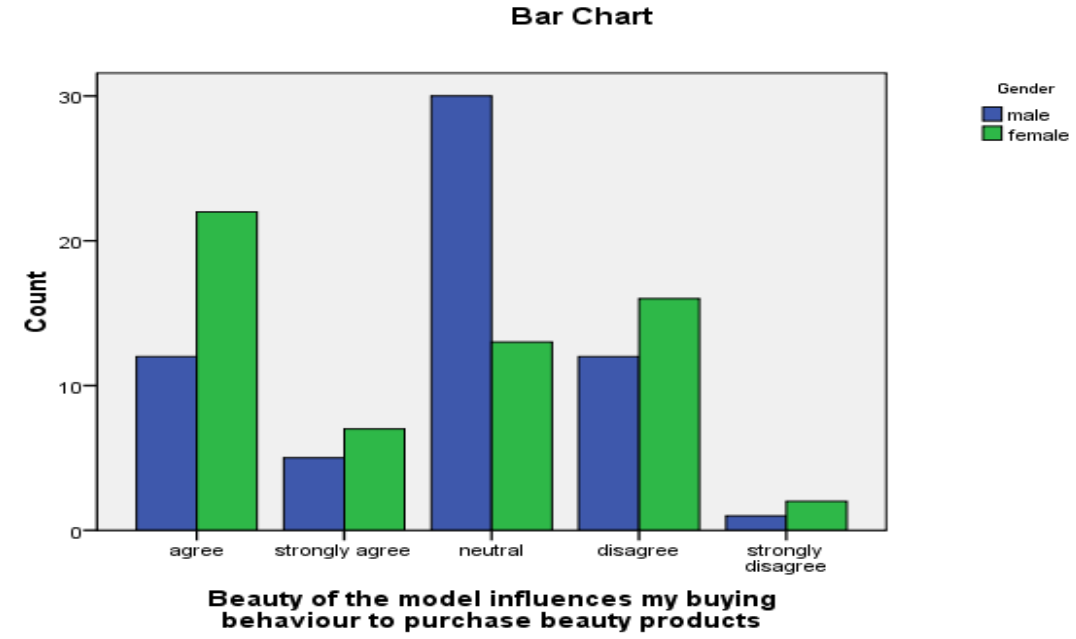

Table 7designed to know the influence on the purchasing behavior of people due to beauty of model. Majority of the respondents gave neutral response in which $13 \%$ were males and $30 \%$ were males.225 females and $12 \%$ males agreed that beauty of the model influence their purchasing behavior. While $28 \%$ respondents 
disagreed on this in which $16 \%$ females and $12 \%$ males disagreed and only $2 \%$ females and $1 \%$ males strongly disagreed on this. So through this table we concluded that respondent's were not influenced by beauty of model because they gave neutral response.

Do friends and family members influence the type of beauty products that you bu
* Gender Cross tabulation
\begin{tabular}{|l|r|r|r|}
\hline & Gender & & Total \\
\hline & male & female & \\
\hline Agree & 22 & 24 & 46 \\
\hline strongly agree & 6 & 4 & 10 \\
\hline Neutral & 22 & 18 & 40 \\
\hline Disagree & 10 & 11 & 21 \\
\hline strongly disagree & 0 & 3 & 3 \\
\hline & 60 & 60 & 120 \\
\hline
\end{tabular}

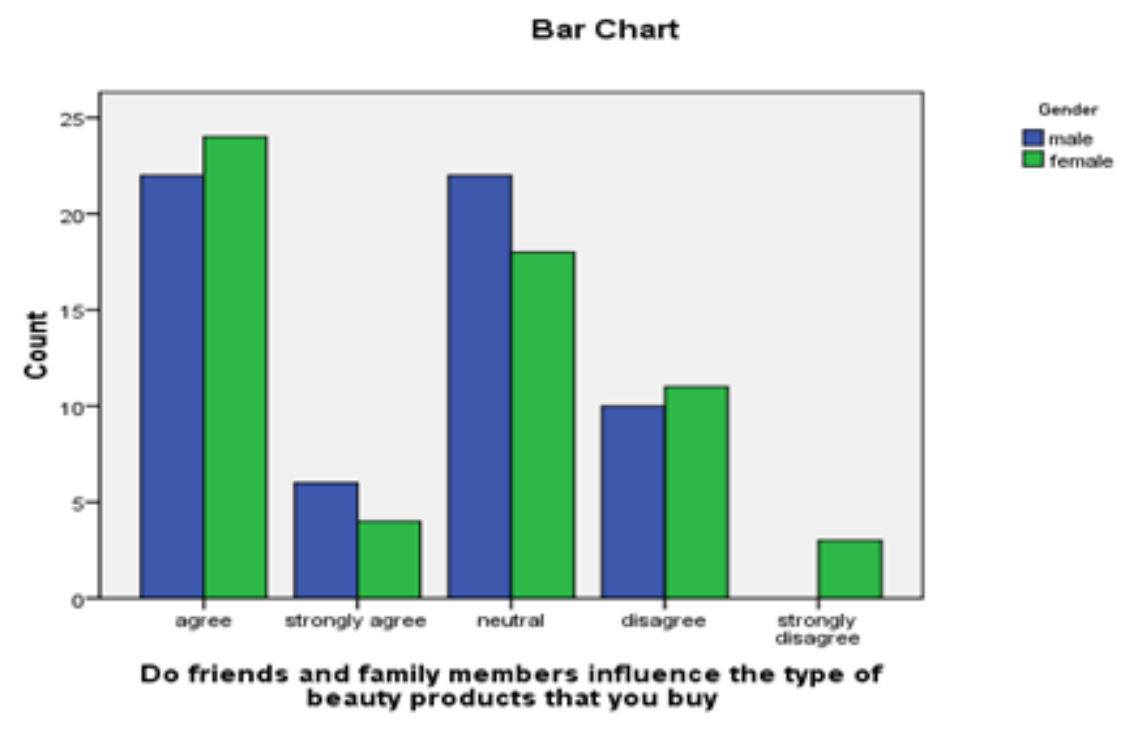

The above table 8.shows influence of friends and family members on the purchasing behavior of people. $46 \%$ respondents gave agreed response. $24 \%$ respondents were females and $22 \%$ were males. On the other hand $40 \%$ respondents neutrally responded on this in which $18 \%$ were females and $22 \%$ were males. While only $3 \%$ respondents strongly disagreed on this in which $3 \%$ were only females? So we can say that friends and family members influence the purchasing behavior of people to some extent.

I am inspired by the quality of beauty products * Gender Cross tabulation.

\begin{tabular}{|l|r|r|r|}
\hline & Gender & & \multicolumn{1}{|c|}{ Total } \\
\hline & male & female & \\
\hline Agree & 31 & 28 & 59 \\
\hline strongly agree & 15 & 12 & 27 \\
\hline Neutral & 11 & 15 & 26 \\
\hline Disagree & 3 & 3 & 6 \\
\hline strongly disagree & 0 & 2 & 2 \\
\hline & 60 & 60 & 120 \\
\hline
\end{tabular}




\section{Bar Chart}

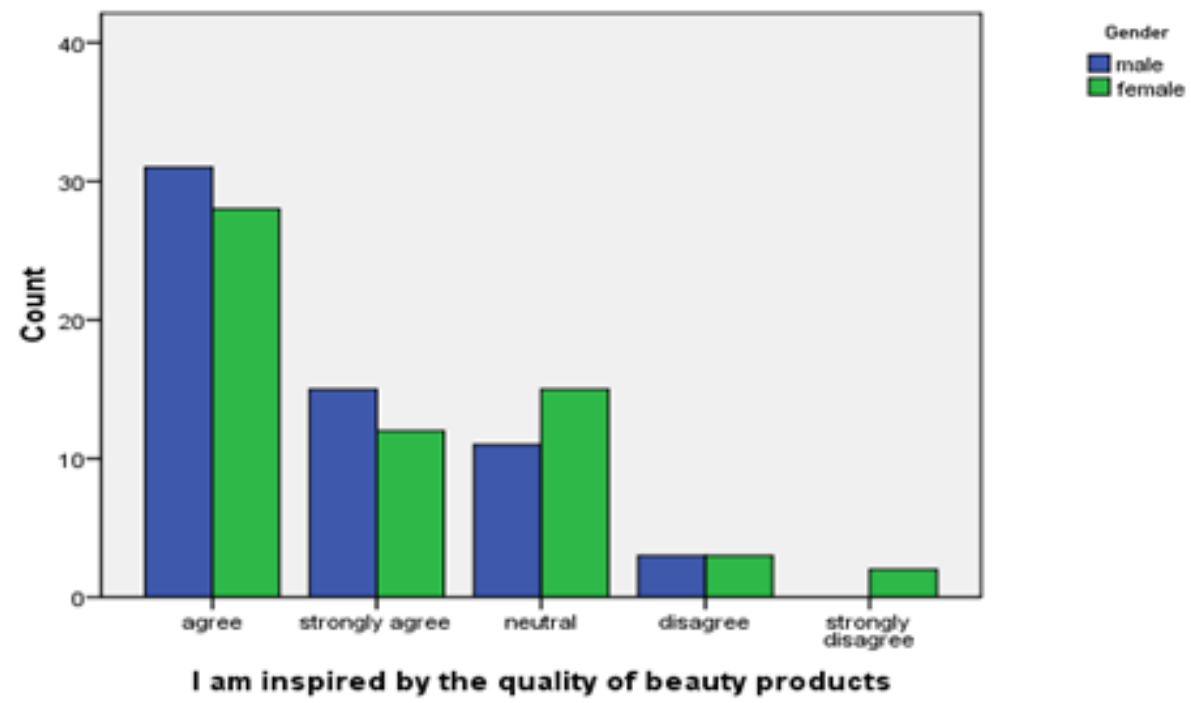

This table shows that how much quality of beauty products inspired the respondents.59\% respondents agreed on this in which $31 \%$ were females and $28 \%$ were males. While $12 \%$ females and $15 \%$ males strongly agreed on this. $15 \%$ females and $11 \%$ males gave neutral response. While only $2 \%$ respondents were strongly disagreed on this in which $2 \%$ were females only? So this table shows that majority of the respondents both males and females are inspired by the quality of products.

I am inspired by the brands of beauty products * Gender Cross tabulation

\begin{tabular}{|l|r|r|r|}
\hline & Gender & & \multicolumn{1}{|c|}{ Total } \\
\hline & male & female & \\
\hline Agree & 30 & 22 & 52 \\
\hline strongly agree & 18 & 19 & 37 \\
\hline Neutral & 10 & 12 & 22 \\
\hline Disagree & 2 & 5 & 7 \\
\hline strongly disagree & 0 & 2 & 2 \\
\hline & 60 & 60 & 120 \\
\hline
\end{tabular}
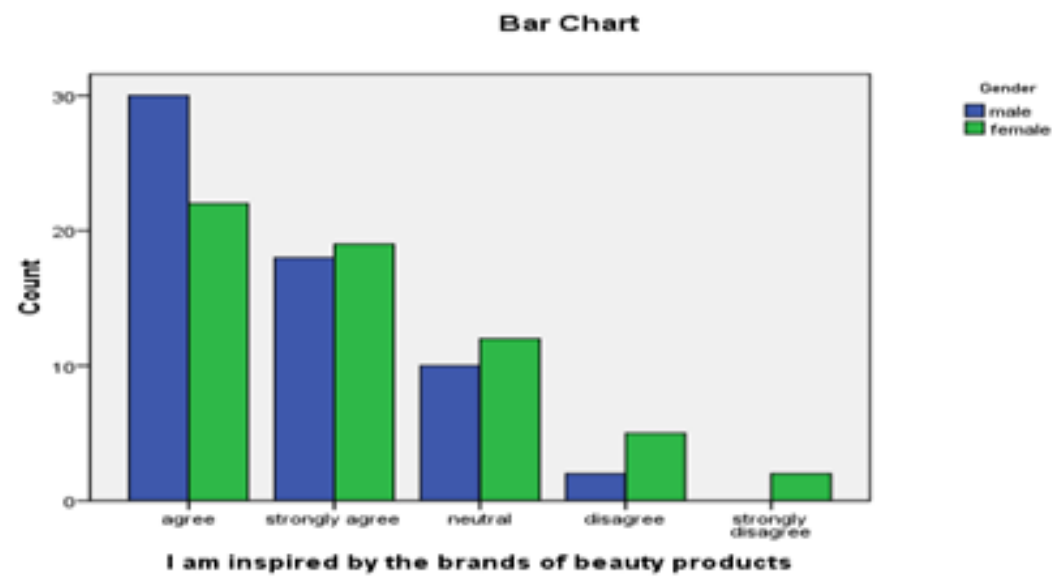

This table was set to know the influence on respondents due to brands of beauty products. Majority of the respondents agreed and $22 \%$ were females and $30 \%$ were males. While $37 \%$ respondents were strongly agreed on this in which $19 \%$ were females and $18 \%$ were males. While only $7 \%$ respondents disagreed on this in which only 55 were females and $2 \%$ were males. While only $2 \%$ respondents were strongly disagreed on this 
in which $2 \%$ were females only? It means majority of the respondents inspired through brands of beauty products. Here males are in majority as compared to female.

If the package of beauty product is attractive to me, I will buy it regardless
\begin{tabular}{|l|r|r|r|}
\hline & Gender Cross tabulation \\
\hline & male & female & \\
\hline Agree & 20 & 25 & Total \\
\hline strongly agree & 10 & 8 & 18 \\
\hline Neutral & 19 & 13 & 32 \\
\hline Disagree & 10 & 11 & 21 \\
\hline strongly disagree & 1 & 3 & 4 \\
\hline & 60 & 60 & 120 \\
\hline
\end{tabular}

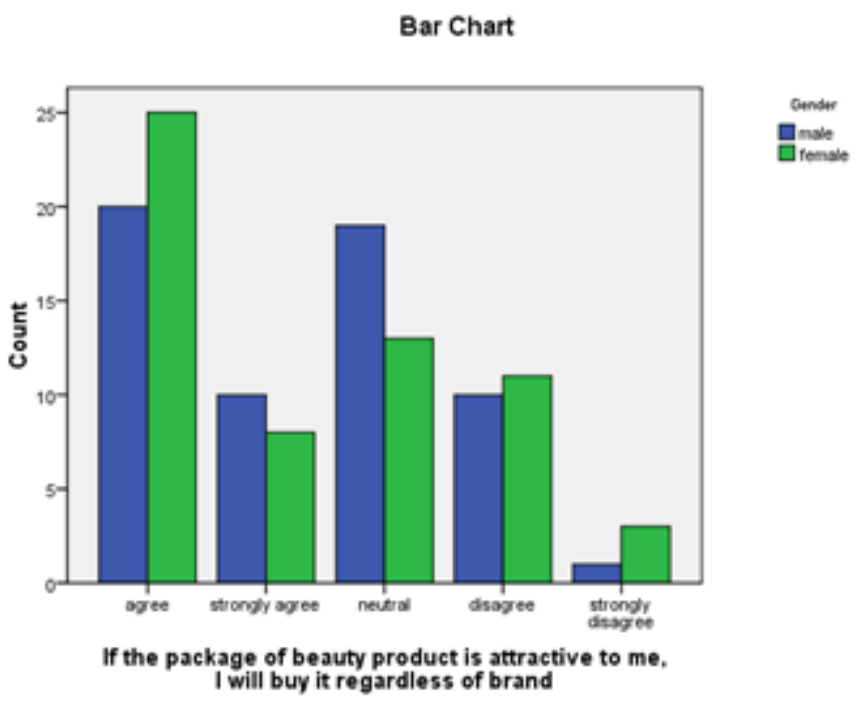

This table predicts that package of beauty product attracts the respondents regardless of brand.25\% females and $20 \%$ males agree that they are influenced by package of beauty products. While $32 \%$ respondents gave neutral response in which $13 \%$ were females and $19 \%$ were males. Only $4 \%$ respondents gave strongly disagree response in which $3 \%$ were females and only $1 \%$ were males. So this table concludes that females are more influenced through package of beauty products regardless of brand.

Price of beauty products affects my purchasing choices * Gender Cross tabulation

\begin{tabular}{|l|r|r|r|}
\hline & Gender & & Total \\
\hline & male & female & \\
\hline Agree & 23 & 31 & 54 \\
\hline strongly agree & 14 & 12 & 26 \\
\hline Neutral & 14 & 12 & 26 \\
\hline Disagree & 6 & 5 & 11 \\
\hline strongly disagree & 3 & 0 & 3 \\
\hline & 60 & 60 & 120 \\
\hline
\end{tabular}




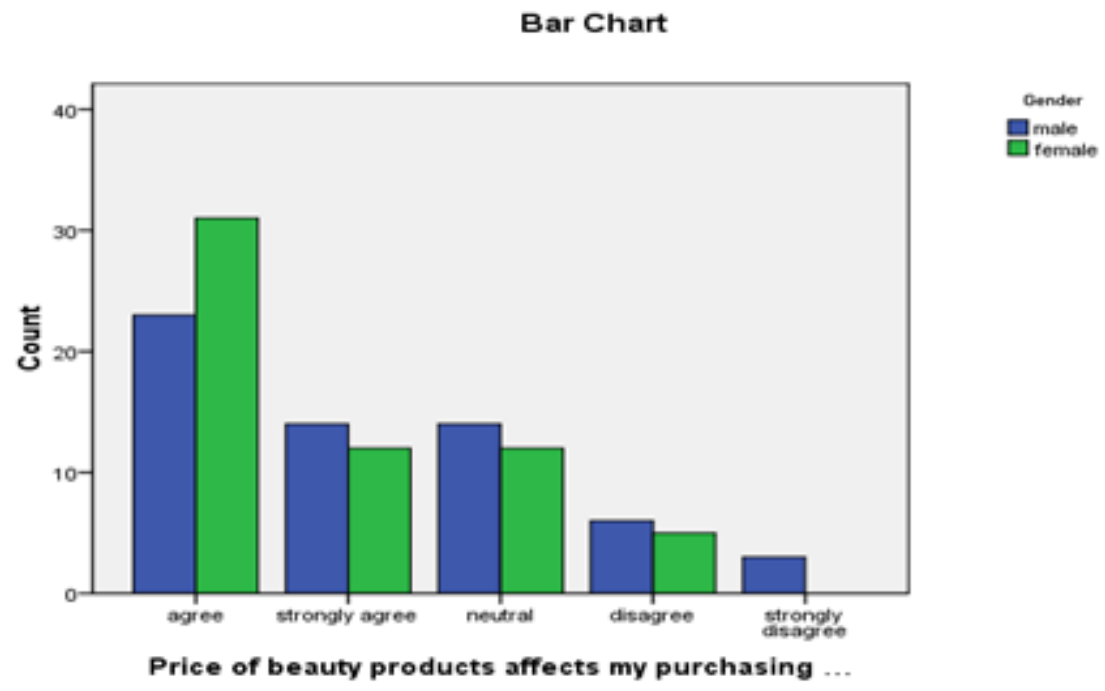

This table shows that price of beauty products affects the purchasing choices of people. Majority of the respondents agreed on this in which $31 \%$ were females and $23 \%$ were males. While $26 \%$ respondents were strongly agreed and $26 \%$ were neutrally respond on this question. While only $3 \$$ respondents gave strongly disagreed on this in which $3 \%$ were males only. $11 \%$ respondents were disagreed in which $5 \%$ were females and $6 \%$ were males only. So we can say that females are mostly influenced by price in purchasing choice.

\section{I only purchase beauty products that I really need * Gender Cross tabulation}

\begin{tabular}{|l|r|r|r|}
\hline & \multicolumn{1}{|c|}{ Gender } & & \multicolumn{1}{c|}{ Total } \\
\hline & male & female & \\
\hline Agree & 28 & 26 & 54 \\
\hline strongly agree & 16 & 7 & 23 \\
\hline Neutral & 12 & 12 & 24 \\
\hline Disagree & 3 & 14 & 17 \\
\hline strongly disagree & 1 & 1 & 2 \\
\hline & 60 & 60 & 120 \\
\hline
\end{tabular}

\section{Bar Chart}

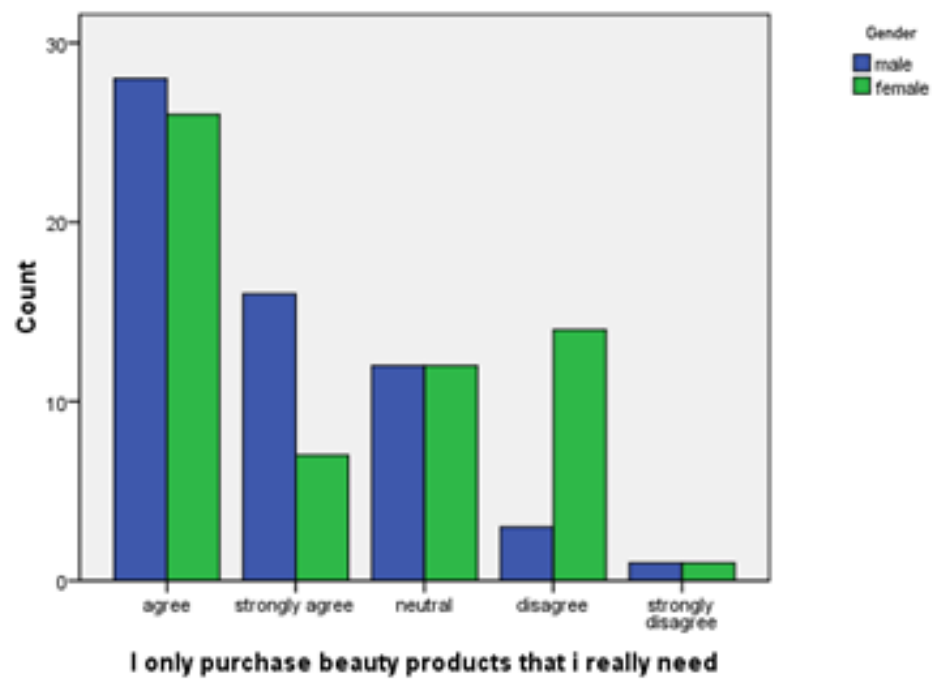

This table shows that respondents purchase only products that they really need.26\% females and $28 \%$ males agreed on this question. While only $2 \%$ respondents gave strongly disagree response in which $1 \%$ were 
females and $1 \%$ were males. $23 \%$ respondents were strongly agreed in which $7 \%$ were females and $16 \%$ were males. This table concludes that males mostly purchase beauty products that they really need.

\section{It is important to me that beauty products can match my self image} * Gender Cross tabulation

\begin{tabular}{|l|r|r|r|}
\hline & \multicolumn{1}{|c|}{ Gender } & \multicolumn{1}{c|}{ Total } \\
\hline & male & female & \\
\hline Agree & 25 & 33 & 58 \\
\hline strongly agree & 4 & 6 & 10 \\
\hline Neutral & 10 & 11 & 21 \\
\hline Disagree & 10 & 16 & 14 \\
\hline strongly disagree & 17 & 10 & 27 \\
\hline & 60 & 60 & 120 \\
\hline
\end{tabular}
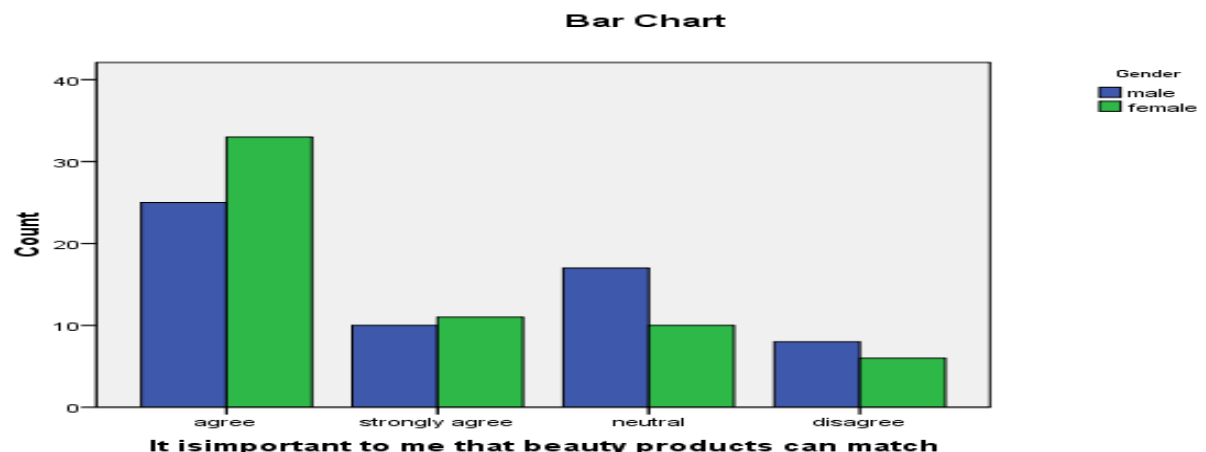

Table no 15 shows that how much self image has importance in purchasing beauty products. Majority of the respondents agreed that in which $33 \%$ wee females and $25 \%$ were males. While only $14 \%$ respondents were disagreed in which $6 \%$ were females and $8 \%$ were males.11 females and $10 \%$ males were strongly purchasing beauty products that match self image.

\section{TV commercials of beauty products are reliable * Gender Cross tabulation}

\begin{tabular}{|c|c|c|c|}
\hline & Gender & & Total \\
\hline & male & female & \\
\hline Agree & 17 & 18 & 35 \\
\hline strongly agree & 4 & 6 & 10 \\
\hline Neutral & 21 & 17 & 38 \\
\hline Disagree & 10 & 16 & 26 \\
\hline strongly disagree & 8 & 3 & 11 \\
\hline & 60 & 60 & 120 \\
\hline
\end{tabular}

Bar Chart

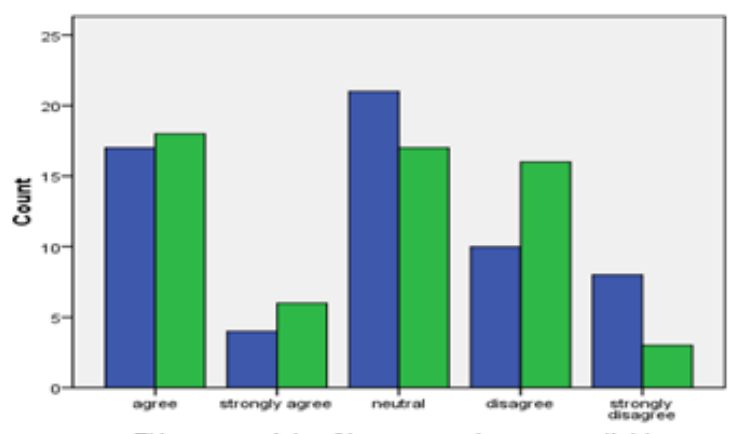

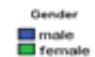

TV commereials of beauty products are reliable 
Table 15.shows reliability of TV commercials towards audience Majority of the respondents gave neutral response in which $18 \%$ were females and $17 \%$ were males..35\% respondents were agreed on the reliability of TV commercials in which $18 \$ \%$ were females and $17 \%$ were males. Only $11 \%$ respondents were strongly disagreed in which $3 \%$ were females and $8 \%$ were males. So we can conclude that males and females don't believe on the reliability of TV commercials because they gave neutral response.

I always want to use those beauty products which I saw in TV commercial * Gender Cross tabulation

\begin{tabular}{|c|c|c|c|}
\hline & Gender & & Total \\
\hline & male & female & \\
\hline Agree & 11 & 21 & 32 \\
\hline strongly agree & 8 & 4 & 12 \\
\hline Neutral & 18 & 18 & 36 \\
\hline Disagree & 20 & 10 & 30 \\
\hline strongly disagree & 3 & 7 & 10 \\
\hline & 60 & 60 & 120 \\
\hline
\end{tabular}

\section{Bar Chart}

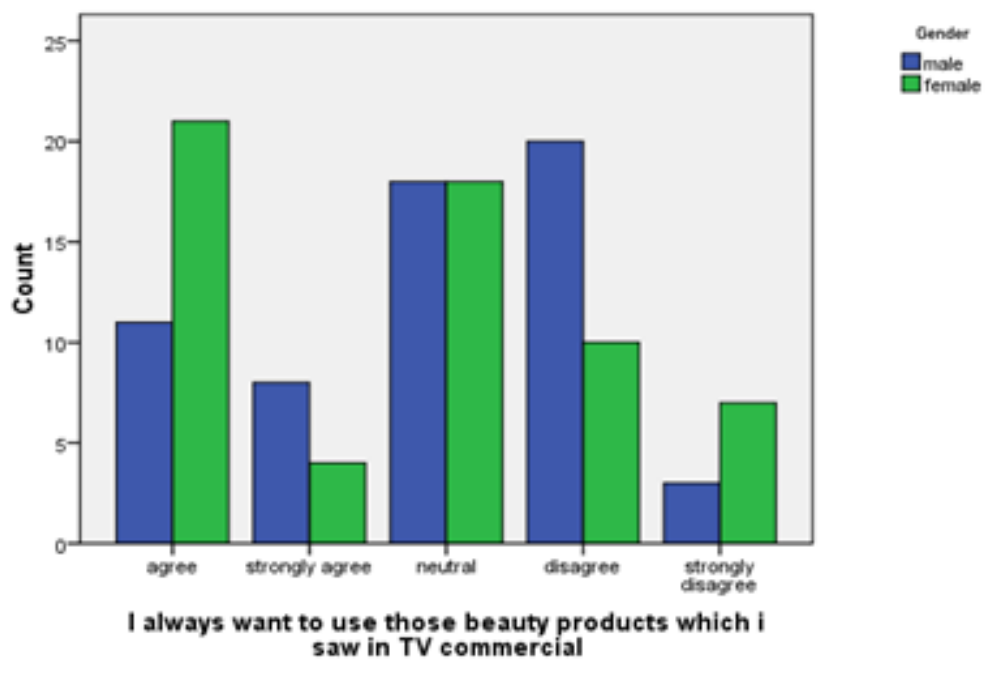

Table17.shows that respondents purchase beauty products after seeing TV commercials.36\% respondents gave neutral response in which $18 \%$ were females and $18 \%$ were males. $32 \%$ respondents showed agreed response in which $21 \%$ were females and $11 \%$ were males. While $10 \%$ females and $20 \%$ males were not agreed and $7 \%$ males and $3 \%$ males were strongly disagreed. So this table concludes that TV commercials not influenced both female and male while purchasing beauty products.

\section{Summary and discussions}

This study aims to determine the message discrimination on gender on the basis of beauty product's TV commercials. To achieve the objectives of the study target population was selected from the University of Gujrat with the sample size of 120 in which 75 were males and 75 were females. This study revealed that both males and females have high exposure towards TV and both are influenced by the TV commercials of beauty products. The question. 1 was designed to find out the exposure of males and females towards TV. It was proved through analysis that TV is the most effective medium for both the genders males and females. But as table1.shows that majority of the males and females have exposure towards TV. But females have more exposure towards TV as compared to males.Females have more exposure towards TV commercials of beauty products as compared to females. Perception of both male and females towards beauty products is different. As the above table. 2 shows that $29 \%$ of the females like to watch TV commercials of beauty products as compared to $15 \%$ of males.

This study supported the studies conducted by Kotwal, Gupta, Devi (2008), Rahman, Khattak and Khan,(2009) and Anna j. in 2008) in all of these studied researchers found that TV advertisement have powerful influence on audience. And females have more interest in TV commercials of because they found them more entertaining and informative. This can also be supported through Anna j. study in 2008 where he found that 
females are more influenced by media images such as TV commercials and results of that study revealed that $46 \%$ of females influenced through TV advertisement as compared to $25 \%$ of males.Females are more affected by TV commercials of beauty products than males are. Table. 3 also shows that $31 \%$ of the females are influenced by the TV commercials of beauty products as compared to $12 \%$ of males. The same results were also derived by the Raza and Ali in their research in 2011.This study found that there is significant relationship exists between beauty advertising and buying behavior and females have more attraction towards beauty advertising as compared to males.These results also supported the hypothesis that females are more influenced by the TV commercials of beauty products as compared to males.According to both male and female beauty of the model have no influence by the purchasing behavior of audience. Because majority of the people in audience neutrally responded on this question.Both male and female are inspired by the quality of beauty products. But most of females are inspired by the quality of beauty products.Males are more inspired by the brands of beauty products as compared to females. As in above table shows that 59\%of total respondents agreed that they are inspired by the brands of beauty products in which $30 \%$ were males while females were $22 \%$.it means males are more inspired by the brand recall while purchasing any beauty product. And these findings are also opposing The Hague's study in 2012 where he found females have better brand recall as compared to males and prefers to purchase beauty products by inspiration of its brand.Due to the prices there are more females as compared to males who make their purchasing decision. As it is clearly shown in the above table, where majority of the respondents who agree are females $31 \%$ as compared to males $23 \%$.it means prices matters to respondents a lot and influence their purchasing decision.

Males prefer to purchase beauty products according to their needs while females are not. As it can be understand through the table. Where majority of the respondents gave positive response in which $28 \%$ are males and $26 \%$ are females.Females give more importance to their self-image while purchasing beauty products. In the above table. $33 \%$ females agreed that they purchase beauty products that match their self image as compared to males who are $25 \%$.As compared to females, males perceive that TV commercials are not reliable and don't portray the true picture of beauty products.38\% respondents disagreed to accept the reliability of TV commercials in which $17 \%$ were female respondents and $21 \%$ were males. As it is opposed to the findings of (Haque, 2012) where majority of the respondents especially females agreed that TV advertisements are true and they believe on it. This shows that how much difference is in the perception of both the genders.Both males and females were neutral on purchasing the beauty products after seeing in TV commercials. Because in table 16 majority of the respondents gave neutral response in which $18 \%$ were males and females respectively.

\section{Conclusion}

As this study mainly focuses on the TV commercials so further researches can be conducted on the Internet because of its popularity now a days. Further researches can also be conducted on print media advertisement. But in this study TV commercials were selected because it is still most influential form of commercials in both males and females. So it is proving the benefits of marketers to focus on the TV commercials for advertising of products because it is popular among audience. As females have more exposure towards TV. So it can be prove benefit of the marketers to target women because women are more influenced by TV commercial of beauty products and also give great importance to beauty products in their life. As it is also proved by conducted this study that both male and female perceive TV commercials differently. So it is necessary that Commercials themed should be set according to target audience perception. Commercials for the males should emphasize on the brands. On the other side, females are mostly affected through the quality of products, Prices, package and styles in which TV commercials are represented. So these elements should be kept in mind by the advertisers.

Study findings revealed there is great impact of brand in beauty products. The further study could focus on the competition between domestic and international brands. This`study is conducted by using likert scale format only. While further studies can be conducted by using face-to face discussions, interviews to obtain more information regarding perception of males and females towards TV ads.

\section{References}

[1]. Admin,(2012). http://irecommendnetwork.com/goto/beauty (Retrieved 15 August, 2012)

[2]. Answers. $\begin{array}{lllll}\text { (n.d.). } & \text { Retrieved } & \text { August 20, 2012, } & \text { from }\end{array}$

http://wiki.answers.com/Q/What_questions_do_not_have_enough_information_to_be_answered_on_WikiAnswers

[3]. Ashudazzaman, M., \& Rehman, S. u. (2009). Impact of TV advertisement on the buying pattern of women in the Dhaka city. European journal of business and management Vol 3 No.3

[4]. Audrey, B., Cyrrielle, C., \& Quentin, L. (2007). The customer behavior in the men's cosmetic market.

[5]. Dissertation in marketing 15 ECTS.

[6]. Bashir, A., \& Malik, N. I. (2009). Effects of advertisement on consumer behavior of University

[7]. students. Proceedings 2nd CBRC.

[8]. Bierley, s. (2002). The advertising. London: Rout ladge

[9]. Chafai, H. (2008). A sociologistical analysis of Women's representation in British and Moroccan Magazine Advertisement. gender and language of advertising 
[10]. Cityweb.(2007). www.citytvweb.com/the-effects-of-television-advertising-to-society (Retrieved $5^{\text {th }}$ September, 2012).

[11]. Cunningham. (n.d). Influence of TV advertising. http://www.ehow.com/info 7753357 influence-televisionadvertising.html (Retrieved $5^{\text {th }}$ September, 2012).

[12]. Daily mail, (2012).http://www.dailymail.co.uk/femail/article-2182768/High-maintenance-men-stealing-products-One-boys-admitusing-partners-beauty-buys.html

[13]. (Retrieved 25 August, 2012)

[14]. Easy outline to TV commercial. (n.d.). Retrieved September 3rd, 2012, from Laws.com: http://commercial.laws.com/tvcommercialExplorable.com, (n.d).http://explorable.com/operationalization.html

[15]. (Retrieved 14 September,2012)

[16]. Gentry, W.J, Haley A.D.(1984), Gender schema theory as a predictor of ad recall::Advances in Consumer Research Volume 11, Pages 259-264

[17]. Investwords. (2012). http://www.investorwords.com/3738/population.htm (Retrieved 3rd September, 2012)

[18]. K Mohan, (2011).India study channel. Http://www.indiastudychannel.com/forum/76726-

[19]. (Retrieved 26 August, 2012).

[20]. Raza, A., \& Ali, F. (2011). Attraction of students towards beauty products. Australian Journal of business and management research Vol 1 No.3.

[21]. Rivera, M. M., \& Rivera, R. V. (2007). Practical guide to thesis and dissertaion writing. Quezon city Philippines: KATHA publishing inco.

[22]. Russell, J.T., Lane, W.R. (1998). Kleppner's Advertising Procedure, 10th ed. Upper Saddle River, NJ: Prentice-Hall.

[23]. Khattiyanon, T. (2011). A study of TV commercials influence on Thai women's purchasing decision of anti aging cream products. Business English for International communication .

[24]. kilbourne, J. (1990). Central for media literacy. Central for media literacy,Beauty....and beast of advertising issue\#49 Media \& Values Redesigning women .

[25]. Kotwal, N., Gupta, N., \& A. D. (2008). Impacts of TV advertisement on the buying pattern of adolescent girls. Kalma-Raj(2008)-JSCI , 51-55.

[26]. laws.com, (n.d).easy outline to TVcommercial. http://commercial.laws.com/tv-commercial retrieved 3rd September, 2012

[27]. Lipsitz, S.B. (1981a). "Gender Schema Theory: A Cognitive Account of Sex-Typing. Psychological Review, 88 No. 45.354 - 364.

[28]. Marketerresearchworldhttp://www.marketresearchworld.net/index.php?option=com_content\&task=view\&id=2547\&Itemid=77 (Retrieved 3rd September, 2012)

[29]. Maxwell A., J. (2004).qualitative research design: an interactive approach.2nd edition. SAGE publications.

[30]. Mishra, A. (2009). International journal of marketing studies Vol 1 No 2. Indian perspective about advertising appeal .

[31]. Moungkhem, C., \& Surakiyapinyo, J. (2010). A study of the factors affeeting men's skin care products.

[32]. NCBI, http://www.ncbi.nlm.nih.gov/pubmed/7869225 (Retrieved 3rd September, 2012)

[33]. National institute, National Institute on Media and the Family (Retrieved 27 August, 2012)

[34]. Oakley, H. (2009). An evaluation of current techniques in cosmetics advertising and an assessment of their effectiveness on the contemporary consumers. Edinburgh Napier University.

[35]. Operationalization. $\quad$ (n.d.). $\quad$ Retrieved $\quad$ Saeptember 14 th, http://explorable.com/operationalization.htmlOlzyk, E., \& Twadowska. (2000).Women and media: Polish women in the 90'S report of the women's rights center. Retrieved from $h t t p " / /$ temida.free.ngo.pl/media.html

[36]. Pandey, k. (2011). Impacts of celebrity endorsement on young generation through TV advertisement. VSRD International journal of business \& Management research .

[37]. The free dictionary. (n.d). http://www.thefreedictionary.com/television(Retrieved 25 August, 2012)

[38]. Patley, J. (2004). Advertising. London, England: Hodder Wayland.

[39]. kallet, R. H. (2004, 11). how to write a method section of a research paper. Respiratory care services.Vol 4No.10 .Taylor, D. (n.d.). The literature review:A few tips on conducting it. Retrieved September 10th, 2012, from http://www.writing.utoronto.ca/advice/specific-types-of-writing/literature-review

[40]. What are demographics. (2012). Retrieved August 3rd, 2012, from Want to know it: ) http://wanttoknowit.com/what-aredemographics

[41]. Wimmer, R. D., \& Dominick, J. R. (2010). Mass media research:An introduction. United States Of America: Michael Rosenberg.

[42]. World of females. (2012). Retrieved August 5th, 2012, from World of females: http://www.worldoffemale.com/why-most-adshave-female-actors/ 